\title{
Superoxide-imbalance pharmacologically induced by Rotenone triggers behavioral, neural, and inflammatory alterations in the Eisenia fetida earthworm
}

\section{Moisés Henrique Mastella}

Universidade Federal de Santa Maria https://orcid.org/0000-0001-6990-6079

Isabel Roggia

Universidade Federal de Santa Maria

Bárbara Osmarin Turra

Universidade Federal de Santa Maria

Cibele Ferreira Teixeira

Universidade Federal de Santa Maria

Charles Elias Assmann

Universidade Federal de Santa Maria

Luciano de Morais-Pinto

Universidade Federal de Santa Maria

Taís Vidal

Universidade Federal de Santa Maria

Cinthia Melazzo

Universidade Federal de Santa Maria

Ivo Emílio da Cruz Jung

Universidade Federal de Santa Maria

\section{Fernanda Barbisan}

Universidade Federal de Santa Maria

Ivana Beatrice Mânica da Cruz ( $\sim$ ibmcruz@hotmail.com )

Universidade Federal de Santa Maria https://orcid.org/0000-0003-3008-6899

\section{Research}

Keywords: Earthworm, Superoxide, Inflammation, Psychiatric Disorders, Neurodegeneration

Posted Date: November 2nd, 2021

DOI: https://doi.org/10.21203/rs.3.rs-968598/v1 
License: (c) (i) This work is licensed under a Creative Commons Attribution 4.0 International License. Read Full License 


\section{Superoxide-imbalance pharmacologically induced by Rotenone triggers behavioral, neural, and inflammatory alterations in the Eisenia fetida earthworm}

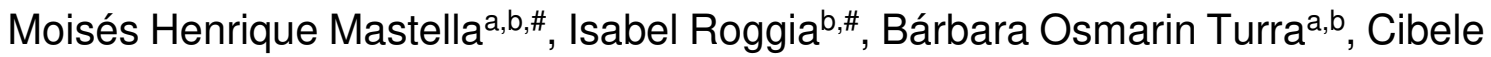
Ferreira Teixeira ${ }^{a, b}$, Charles Elias Assmann ${ }^{b, c}$, Luciano de Morais-Pinto ${ }^{d}$, Taís Vidalc, Cinthia Melazzoc, Ivo Emílio da Cruz Jung ${ }^{b}$, Fernanda Barbisan ${ }^{b, e}$, Ivana Beatrice Mânica da Cruz ${ }^{a, b, e, *}$

aGraduate Program of Pharmacology, Federal University of Santa Maria, Santa Maria, Brazil. bBiogenomics Lab, Health Sciences Center, Federal University of Santa Maria, Santa Maria, Brazil.

'Graduate Program of Toxicological Biochemistry, Federal University of Santa Maria, Santa Maria, Brazil.

dAnatomical Design Laboratory, Morphology Department, Federal University of Santa Maria, Santa Maria, Brazil.

eGraduate Program of Gerontology, Federal University of Santa Maria, Santa Maria, Brazil.

\# These authors contributed equally to this study

* Corresponding author: Ivana BM da Cruz, Av. Roraima 1000, Prédio 19, Santa Maria - RS, Brazil. Zip Code: 97105900 . Phone: +55 55991199099. Email: ibmcruz@hotmail.com

Funding Source: Conselho Nacional de Desenvolvimento Científico (CNPq), Fundação de Amparo a Pesquisa do Rio Grande do Sul (FAPERGS), Coordenação de Aperfeiçoamento de Pessoal de Nível Superior (Capes). 


\section{Abstract}

Background: The inflammatory theory of depression has been tested from epidemiological and experimental investigations. Some studies have suggested that mitochondrial dysfunction superoxide imbalance could increase the susceptibility to chronic stressful events, contributing to the establishment of chronic inflammation and the development of mood disorders. If this premise is true, mitochondrial superoxide imbalance induced by some molecules, such as Rotenone could be evolutionary conservated causing behavioral, immune, and neurological alterations in animals with the primitive central nervous system. Objective: To test this hypothesis, we analyzed some behavioral, immune, and histological markers in Eisenia fetida earthworms chronically exposed to Rotenone, that causes mitochondrial impairment for 14 days. Methods: earthworms were put in an artificial soil containing $30 \mathrm{nM}$ of Rotenone distributed into a plastic cup that allowed the earthworms to leave and return freely into the ground. Since these organisms prefer to be buried in the ground, the model predicted that the earthworm would necessarily have to return to the Rotenonecontaminated medium creating a stressful condition. The effect on survival behavior, in the immune and histological body wall and ventral nervous ganglia (VNG) structures were evaluated, as well gene expression related to inflammation, mitochondrial and neuromuscular changes. Results: Rotenoneinduced loss of earthworm escape behavior triggered by boric acid presence; it caused immune alterations indicatives of chronic inflammatory states. Some histological changes in the body wall and VNG indicated a possible earthworm reaction aimed at protection against Rotenone. Overexpression of the nicotinic acetylcholine receptor gene (nAChRs a5) in neural tissues could also help earthworms to reduce the degenerative impact of Rotenone on dopaminergic neurons. Conclusion: The data suggest that mitochondrial dysfunction could be an evolutionarily conserved element in inducing inflammatory and behavioral changes related to exposure to chronic stress.

Key-words: Earthworm. Superoxide. Inflammation. Psychiatric Disorders. Neurodegeneration. 


\section{Ethics Declarations}

\section{Ethics approval}

Not applicable.

\section{Consent for publication}

Not applicable.

\section{Availability of data and materials}

The datasets used and/or analyzed during the current study are available from the corresponding author on reasonable request.

\section{Competing interests}

The authors declare that they have no competing interests.

\section{Funding}

Conselho Nacional de Desenvolvimento Científico (CNPq), Fundação de Amparo a Pesquisa do Rio Grande do Sul (FAPERGS), Coordenação de Aperfeiçoamento de Pessoal de Nível Superior (Capes).

\section{Authors' contributions}

MHM: Conceptualization, Methodology, Investigation, Writing, Writing - Review \& Editing, Preparation.

IR: Conceptualization, Methodology, Investigation, Writing, Writing - Review \& Editing, Preparation.

BOT: Methodology, Investigation, Visualization.

CFT: Methodology, Investigation, Visualization.

CEA: Methodology, Investigation, Visualization.

LMP: Methodological and investigative support.

TV: Methodological and investigative support.

CM: Methodological and investigative support.

IECJ: Methodology, Investigation, Visualization.

FB: Methodology, Investigation, Visualization.

IBMC: Term, Conceptualization, Formal analysis Application of statistical, Data Curation, Writing - Review \& Editing, Supervision, Project administration Management and coordination responsibility, Funding acquisition.

\section{Acknowledgments}

The authors are thankful to the technique researcher Marina de Souza Vencato, from the Federal University of Santa Maria (UFSM), for the support in this research. 


\section{List of abbreviations}

SNPs: single nucleotide polymorphism

SOD2: manganese-dependent gene superoxide dismutase

CNS: central nervous system

ETs: extracellular DNA traps

hNETs: human neutrophils extracellular DNA traps

ROS: reactive oxygen species

nM: nanomolar

TAS: tropical artificial soil

VNG: ventral nervous ganglion

BOD: bio-oxygen demand

UV: ultraviolet

$\mathrm{cm}$ : centimeter

LBBS: Lumbricus balanced salt solution

$\mathrm{mL}$ : millilitre

$\mathrm{mM}$ : millimolar

PBS: phospate buffer solution

$\mathrm{PI}$ : propidium iodete

VGN: ventral nerve cord ganglion

MGT: Masson-Goldner trichrome

PSR: Picrosirius

$\mathrm{CM}$ : circular muscle

LG: longitudinal muscle

se: segmental nerve

$\mathrm{mg}$ : mucous gland

co: collagen

$\mathrm{TL}$ : trilaminar sheath

SV: sub neural blood vessel

Np: neuropil

sc: satellite cells

$\mathrm{Nb}$ : giante neurons

SeN: sensorial neurons

As: astrocytes

DBP: dark brown pigments

CUMS: chronic unpredictable mild stress

TLR: Toll-like receptors

PRRs: pattern recognition receptor

PAMPs: pathogen-associated molecular patterns

DAMPs: damage/danger-associated molecular patterns 


\section{Introduction}

Neuroinflammatory processes have been linked to several neurological and psychiatric morbidities, including mood disorders such as depression and bipolar disorder. The identification of components that contribute to the initiation, progression, and intensification of neuroinflammatory processes is of great clinical and epidemiological relevance. Previous investigations have suggested that the unbalance of the superoxide anion could be a relevant factor in neuroinflammation.

Chronic exposure to stressful situations is considered a crucial element in the development of psychiatric diseases, especially mood disorders such as depression and bipolar disorder [1]. One of the causal mechanisms linking chronic stress and psychiatric disorders involves the establishment of chronic neuroinflammatory states causing cognitive and behavioral dysfunctions [2]. However, it appears that some individuals are more sensitive to chronic stressful events than others in consequence of negative lifestyle factors, such as diet and sedentarism that contribute to the establishment of chronic inflammatory states $[2,3]$.

In addition to environmental variables, genetic factors that affect the intensity and maintenance of the inflammatory response may also be relevant in the sensibility to chronic stressful events. This is the case of superoxide imbalance triggered by a human single nucleotide polymorphism (SNPs) rs4880 occurring in manganese-dependent gene superoxide dismutase (SOD2). Some authors found an association between the VV-SOD2 genotype, which presents less efficiency in the dismutation of superoxide in hydrogen peroxide. Previous evidence reported in the literature suggested an association between the VVSOD2 genotype with high basal superoxide levels, chronic inflammatory states including elevated levels of pro-inflammatory cytokines [4, 5], and high risk to depression [6-8]. A complementary analysis also suggested that healthy adult subjects carrying VV-genotype of SNP rs4880, which presents high superoxide levels have higher basal stress biomarkers than A-allele carriers, such as cortisol [8]. Moreover, a recent study described that an acute superoxide-hydrogen peroxide imbalance pharmacologically induced in the Eisenia fetida earthworm was able to change some inflammatory and behavioral patterns [9]. 
Therefore, superoxide imbalance could be an evolutionarily conserved component associate with greater sensitivity to exposure to stressful situations by induction of inflammatory and neurobehavioral alterations. To test this hypothesis we also used E. fetida as an experimental model, based on the following considerations: Earthworms are the first animals on the evolutionary scale to have a primitive ganglion central nervous system (CNS) with an extensive network of chemosensors spread throughout the body that help to make decision processes regarding environmental quality. In the presence of toxic or drying agents, earthworms may develop prosocial aggregation mechanisms or may escape the site. For this reason, these animals are consistently used in ecotoxicity assays to determine soil quality [10]. Behavioral studies have also suggested that earthworm decision-making processes are complex and highly individualized, leading to the suggestion that earthworms would be a good model for studies of personality evolution [11].

Moreover, earthworms have a highly competent immune system aimed at destroying infectious pathogens. However, unlike more complex organisms, in the presence of irritating or pathogenic factors, earthworms can spew out a large amount of coelomic fluid that contains immune cells similar to those found in human blood [12]. These cells are called coelomocytes and can even form extracellular DNA traps (ETs) in the presence of biotic or abiotic antigenic elements similar to the networks formed by human neutrophils (hNETs) [13]. Therefore, earthworms can represent a potentially good model in the investigations related to chronic stress and inflammation, since their primitive neural structures are less complex than those found in vertebrate animals.

\section{Methods}

\section{Experimental design and ethical issues}

The superoxide-imbalance in earthworms was triggered by chronic exposure to Rotenone, an isoflavone molecule with crystalline aspect, colorless and odorless. This is a hydrophobic molecule that easily traverses the blood-brain barrier and inhibits mitochondrial complex I of oxidative phosphorylation interrupting mitochondrial electron transport. The mitochondrial respiratory chain 
represents the major source of reactive oxygen species (ROS) in eukaryotic cells, mainly by the constant generation of superoxide anion [14]. Since Rotenone is also used in Parkinson's experimental models [15], to carry out this study, an initial evaluation was carried out that identified the best concentration of this molecule capable of causing alterations without inducing extensive neurodegeneration capable of affecting the locomotion and survival of earthworms. Data from a pilot study that tested a Rotenone curve of concentration $(0,1,10,30,100,300 \mathrm{nM})$ on the viability and locomotor changes indicated that Rotenone at $30 \mathrm{nM}$ was the best concentration to be used in all experiments (Fig. 1A). This concentration was also used in the Jung et al. [9] study allowing possible comparisons between the results of acute and chronic exposure to Rotenone.

The study conducted here was different from the investigation performed by Jung et al. [9], in which earthworms were placed for $24 \mathrm{~h}$ in a Petri dish with filter paper moistened with Rotenone solution. In this experiment, Rotenone solution was mixed with an artificial culture medium distributed into a plastic cup with a $3 \mathrm{~cm}$ space that allowed the earthworms to leave and return freely to the medium containing the Rotenone. Since earthworms continuously swallow soil, prefer to be buried in the ground, and cannot stay long in dry environments, the model predicted that the earthworm would necessarily have to return to the environment Rotenone contaminated. Therefore, this model sought to mimic chronic stressful situations in which people are exposed when they are forced to attend certain work or family environments that generate a high load of stress (Fig. 1B).

To test the effect of Rotenone exposure on survival behavior, on the first, seventh, and $14^{\text {th }}$ day of the experiment, earthworms were subjected to a boric acid escape test. In this test, the earthworm is given the possibility to choose between quality soil without any chemical aversive component and soil contaminated with boric acid that is highly aversive for this animal [10]. Therefore, it is expected that after 48 hours all the earthworms have migrated to the best free-boric acid soil. We avoided performing other behavioral analyzes since most of the trials involve displacement of the worms in less time, and the cumulative effect of Rotenone could strongly interfere with the results. 

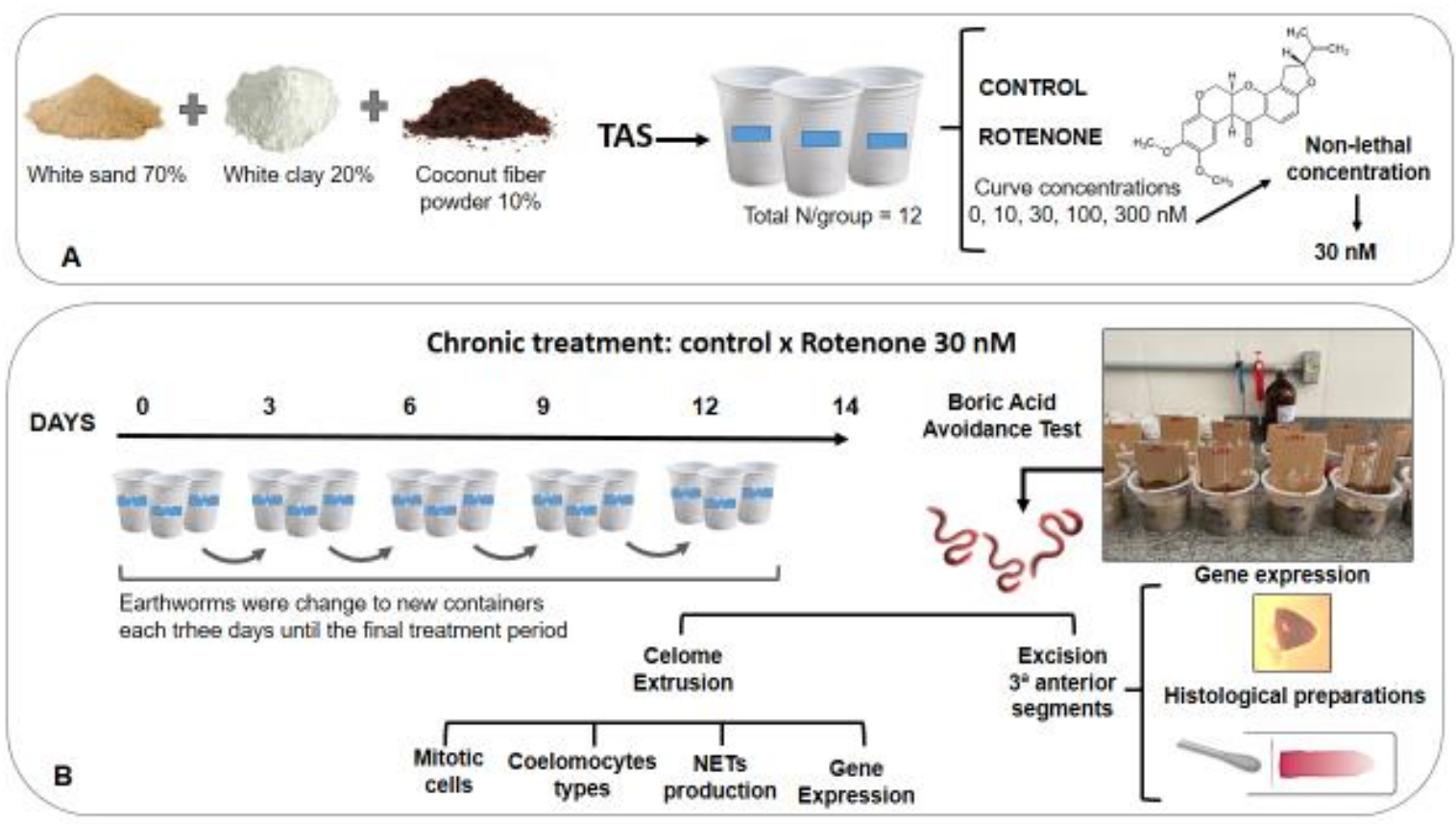

Fig. 1 General experimental design. A Eisenia fetida was exposed to Rotenone at different concentrations and the non-lethal $30 \mathrm{nM}$ concentration was chosen to perform all protocols. B Chronic treatment with Rotenone at $30 \mathrm{nM}$ using a tropical artificial soil (TAS) compounded by white sand, white clay and coconut fibber powder. Every three days the worms were transferred to new containers containing TAS with and without the addition of Rotenone until completing 14 days of exposure. About $3 \mathrm{~cm}$ of each container was not covered with TAS thus allowing the worms to leave and return to the interior of the culture medium. After chronic exposure to Rotenone, the boric acid escape behavior test was performed. Modulation of immune function indicators was evaluated on the $1^{\text {st }}, 7^{\text {th }}$, and $14^{\text {th }}$ day of treatment. On the $14^{\text {th }}$ day, analyzes of potential histological changes in the body wall and neural structures of the earthworm were also performed. The expression of genes related to the immune, mitochondrial and neural function of coelomocytes and structures of the first three anterior segments where the brain ganglion is located was also evaluated in control and earthworms chronically exposed to Rotenone.

Throughout the experiment, analyzes related to the impact of Rotenone on the modulation of the immune metabolism of $E$. fetida were also conducted. Therefore, the following immunocompetence markers were evaluated in the $1^{\text {st }}$, $7^{\text {th }}$, and $14^{\text {th }}$ days from the coelomic fluid extruded by the earthworms: (1) Rotenone effect on coelomocyte proliferation determined by the sum of cells in S and G2 phase by flow cytometry, since a high rate of cells in mitosis indicates a pro-inflammatory state [9]; (2) frequency of major coelomocyte types (amoebocytes and eleocytes) by flow cytometry; (3) qualitative autofluorescence of eleocytes detected by fluorescence microscopy; (4) coelomocyte's ability to form ex vivo NETs in the presence of dead yeasts assessed via optical microscopy; (5) coelomocytes gene expression modulation related to inflammatory response, mitochondrial and neuromuscular function via qt-PCR, described in Table 1. 
As Rotenone pesticide in certain concentrations causes degeneration of dopaminergic neurons being used in animal models of Parkinson's disease [15], histological analyzes of the Rotenone chronic exposure on earthworm's ventral nervous ganglion (VNG) and body wall were also conducted. These analyzes allowed us to identify how much Rotenone could have impacted body structures related to the neuromotor and neurobehavioral activity. Moreover, the analysis allowed us to assess whether there were induced histomorphological changes related to earthworm surveillance in a culture medium where Rotenone was added. To carry out these analyses, after 14 days of treatments, earthworms were euthanized and the sixth initial metamers from the anterior region were cross-cut and used in histological preparations. In this earthworms body region is located the dorsal ganglion and a ventral ganglion that is easier to be identified and analyzed. This is because the dorsal ganglion forms a ring around the pharynx, making it difficult to isolate and analyze it at the microscopic level. Tissue samples from this region were also used to analyze the expression of the same genes analyzed in coelomocytes (Table 1).

In many countries including Brazil is not necessary to have prior approval from Animal Ethics Committee for studies involving earthworms. However, the research was performed, according to EU Directive 2010/63/EU for animal experiments.

\section{Earthworms rearing conditions and treatments}

The earthworms rearing was performed in similar conditions previously described by Jung et al. [9]. Briefly, these animals were commercially obtained were transferred, and acclimated in the Laboratory of Biogenomics, Federal University of Santa Maria, Brazil. The acclimatization period was greater than seven days being done inside in a Bio-Oxygen Demand (BOD) at $20^{\circ} \mathrm{C} \pm 1^{\circ} \mathrm{C}$ temperature. Before the experiment, the earthworms were kept in small plastic boxes $(18.5 \mathrm{~cm} \times 18.5 \mathrm{~cm} \times 6.5 \mathrm{~cm})$ protected from the light containing sterilized soil and cattle manure (10:1 proportion) at $80 \%-85 \%$ humidity. Approximately $500 \mathrm{~g}$ of this wet soil was placed in each container.

All experiments used clitellate animals. The chronic Rotenone-stressful assay was performed using a tropical artificial soil (TAS) that includes included 
fine white sand (70\%), white clay (20\%), and coconut fibbers powder (10\%) [16]. Before use, TAS was sterilized in an oven heated to $180^{\circ} \mathrm{C}$ for 30 minutes with manual agitation in half the time. Further, the container with sand was cooled and transferred to the flow chamber for additional ultraviolet (UV) sterilization. In separate containers, sand, clay, and fibbers remained for 40 minutes, a height of $1 \mathrm{~cm}$ with manual agitation in half the time. The components of the TAS were weighed and placed in circular plastic containers (basal diameter $7 \mathrm{~cm} /$ height $=$ $8 \mathrm{~cm})$ previously identified in triplicate containing four earthworms $(n=12)$. The treatment solutions were prepared in a standard volume to obtain, within the container, a humidity of $90 \%$. For the experiment, Rotenone was solubilized in the control vehicle composed of Lumbricus balanced salt solution (LBSS), as described in Engelmann et al. [17], and subsequently mixed in the TAS and manually homogenized for three minutes. Then, the worms were randomly selected and transferred to control or Rotenone groups. Three replicates were made with four earthworms in each container.

To avoid the loss of Rotenone activity and the drying out of the culture medium, earthworms were transferred every three days. This periodic exchange from one container to another also contributed to the generation of stress in the animals. The procedure was repeated four times during the 14 days of the experiment $\left(3^{\text {rd }}, 6^{\text {th }}, 9^{\text {th }}\right.$, and $12^{\text {th }}$ day), in which the earthworms were transferred to new containers containing artificial medium treated or not with Rotenone prepared again.

\section{Boric acid avoidance test}

This behavioral assay was performed according to standard ISO 17512-1 (2008). Briefly, two TAS soils were prepared with humidity of $60 \%$ using just LBBS or LBSS with the addition of boric acid $\left(\mathrm{H}_{3} \mathrm{BO}_{3}\right) 750 \mathrm{mg} / \mathrm{Kg}^{-1}$ [16]. The polypropylene vessels of circular base (basal diameter: $10 \mathrm{~cm}$, height: $8 \mathrm{~cm}$, capacity: $0.350 \mathrm{~L}$ ) containers were, in an upright position, filled with half of each type of TAS soil, separated by a partition and packed in BOD at $20^{\circ} \mathrm{C}$ for better soil fixation for 2 hours. Further, the partition between the two soils was removed to allow free transit between both sides. The earthworms $(n=6)$ by three replicates were released on the remaining dividing line, then the containers were 
sealed and returned to the incubator. After 48 hours, the partition was reinserted, and each side of the soil was removed separately so that it was possible to count the earthworms present on each side. Earthworms that remained in the middle of the dividing line at the time of insertion have a validated count for the side where the anterior region of the body is located.

\section{Immune metabolism assays}

The following immune metabolism assays were conducted in earthworms' Rotenone and non-Rotenone chronically exposed. All analyzes related to immune metabolism were conducted from the obtainment of extruded coelomic fluid via exposure to ether according to the protocol described by Alves et al. [18]. Briefly, the worms were transferred to a $15 \mathrm{~mL}$ falcon tube capped with a cotton bud soaked in ether and closed for two minutes. This time was enough for the extrusion of the coelomic fluid to occur. Further, the tubes were opened, $2 \mathrm{~mL}$ of LBSS containing $5 \mathrm{mM}$ EDTA, was added to prevent the immediate aggregation of the coelomocytes on the tube wall. The earthworms were removed from the tube, and fluid coelom was centrifuged at $250 \times \mathrm{g}$ for 2 minutes to remove any impurities and used in the following protocols involving immune analysis:

(1) Modulation of coelomocytes proliferation by cell cycle analyses using flow cytometry in a similar protocol described by William-Faltaos et al. [19]. Briefly, coelomocyte cells were washed in PBS and resuspended in $70 \%$ ethanol (the suspension was placed in the vortex) and kept at $-20{ }^{\circ} \mathrm{C}$ overnight. Before analysis, the coelomocytes were centrifuged and washed once with PBS, before being resuspended in $500 \mu \mathrm{L}$ PI solution in PBS: $50 \mu \mathrm{g} / \mathrm{mL}$ PI from $50 \times$ stock solution $(2.5 \mathrm{mg} / \mathrm{mL} 0.1 \mathrm{mg} / \mathrm{mL}$ RNase A $0.05 \%$ Triton X-100) and incubated for $40 \mathrm{~min}$ at $37^{\circ} \mathrm{C}$. Finally, $3 \mathrm{~mL}$ of PBS was added for washing and the cells were resuspended in $500 \mu \mathrm{L}$ PBS in preparation for flow analysis. Differential modulation of the mitotic index can indicate the presence of inflammatory or immunosuppressive states triggered by chronic Rotenone exposure.

(2) frequency of main coelomocyte types (eleocytes and amoebocytes) also determined by flow cytometry according to the protocol previously described by 
Engelmann et al. [12] with some modifications performed by Alves et al. [18]. Briefly, the celomic fluid collection was obtained from worms transferred to a 15 $\mathrm{mL}$ falcon tube capped with a cotton bud impregnated with ether and closed. After $2 \mathrm{~min}$, the tubes were opened, $2 \mathrm{~mL}$ of LBSS containing $5 \mathrm{mM}$ EDTA was added to prevent the immediate aggregation of the coelomocytes on the tube wall. After the worm's remotion of the tubes, the extruded coelom was centrifuged (250xg for $2 \mathrm{~min}$ ) to remove potential impurities. The tubes were then gently agitated so that the pellet and the supernatant were homogenized again and used to flow cytometry analysis concerning the cellular size and granulometry. Cells were sorted according to their forward scatter/side scatter (FSC/SSC) patterns using a FACSCanto $^{\text {TM }}$ II Flow Cytometer (BD Biosciences, San Diego, CA, USA). Data acquisition and cell content analysis were performed using FlowJo vX.0.7 software (Tree Star, Inc., Ashland, OR, USA).

(3) Frequency of autofluorescent eleocytes: earthworms contain large eleocytes (chloragocytes) that participate in metabolism and storage of glycogen and lipids transporting nutrients by coelomic fluid and body tissues and also have a functional role in the regeneration after autotomy or amputation of posterior segments, including VNG ganglia [20]. Autofluorescence is triggered by the storage of a high concentration of riboflavin (vitamin B2), a yellow-green fluorophore pigment storage in these cells [21, 22]. Therefore, a complementary analysis using fluorescence microscopy (green light excitation was performed using a smear on the histological slide of coelomic cells obtained as previously described and fixed with ethanol $70 \%$.

(4) Ex vivo NETs assay - This assay was performed as previously described by Alves et al. [18] with some modifications. Briefly, coelomocyte extracted (1000 $\mu \mathrm{L}$ ) from earthworms previously exposed or not to Rotenone were seeded into two 6 -well plates $(1 \times 107$ cells $/ \mathrm{mL})$ with DMEM medium supplemented $(10 \%$ FBS and $1 \%$ antibiotic) and incubated for $2 \mathrm{~h}$ at $27^{\circ} \mathrm{C}$ in a BOD under humid conditions. Further, $40 \mu \mathrm{L}$ of hot boiling inactivated yeast suspension $(1 \times 107$ cells $/ \mathrm{mL}$ ) was added to each well and left for $2 \mathrm{~h}$. After this procedure, the monolayer of each plate was washed with PBS and stained using a Fast Panoptic kit (FPK) (LaborClin, PR, Brazil) - according to the manufacturer's instructions. 
For all of the three solutions, $1000 \mu \mathrm{L}$ was added to the cultures for $10 \mathrm{~s}$. The excess was gently removed using a Pasteur pipette, the plates were washed with PBS, dried, and analyzed by optic microscopy (100x and $200 \times$ magnification) using a Leica DMI 4000B microscope (Leica Microsystems GmbH, Wetzlar, Germany). In order to confirm the presence of ETs another plate was fixed only with the first solution of FPK using the same procedure and stained with fluorescent dye using Quant-iT ${ }^{\mathrm{TM}}$ PicoGreen ${ }^{\circledR}$ dsDNA Reagent Kit (Invitrogen, USA) which has a high affinity to dsDNA molecules being used to identify extracellular DNA-based components, such as mitochondrial nucleoids, in living cells [23]. In this assay $20 \mu \mathrm{L}$ of PicoGreen® dye diluted in $10 \mathrm{mM}$ Tris $/ \mathrm{HCl}$ was added in each well $(100 \mu \mathrm{L})$ and the plate was stored in the dark at room temperature for 60 minutes. Further, the ETs present were imaged under fluorescent microscopy (500-565 nm).

\section{Histological preparations}

The earthworms' CNS is composed of bilobed cerebral ganglion connected to the circumpharyngeal connectives followed by the suboesophageal ganglion and the nerve cord extended throughout the length of the animal [24]. The sensory perception of the environmental stimuli is carried out mainly by the sensory nerve fibbers residing in the ventral nerve cord ganglion (VGN) [25]. Therefore, to identify how much changes in the behavior of earthworms exposed to Rotenone would be linked to extensive neurological changes the histological patterns of the VGN located in the first three anterior metameres were analyzed. Moreover, the potential effect of Rotenone on body wall structure was also evaluated here. Animals were anesthetized in very cold water $\left(\leq 2^{\circ} \mathrm{C}\right)$ for two minutes. After rapid muscular stiffening, the earthworms were transferred to Petri dishes and with the aid of a stereomicroscope cut transversely in the anterior region of the body at the height of the $6^{\text {th }}$ body segment. Soon after they were euthanized with $96 \%$ alcohol. The segments were then transferred to a $4 \%$ formalin solution for $72 \mathrm{~h}$. The fixed body segments were dehydrated using a 15-minute dehydration battery per step with a Kline shaker (GT-20IBSU), with 70\% alcohol, 80\% alcohol, 90\% alcohol, two passages in alcohol anhydrous, alcohol and xylol, and two more passages in xylol. Two hours 
later, the samples were kept in xylol with paraffin, then paraffin 1 and paraffin 2 , being subsequently blocked and kept for drying at room temperature overnight. Histological sections were performed in a semiautomatic microtome (Yd-335) at $7 \mu \mathrm{M}$ thick. The slides were mounted and dried at room temperature overnight for later staining. For histological staining slides underwent a standard dewaxing process, with two passages in xylol heated to $50^{\circ} \mathrm{C}$ (5 min each), anhydrous alcohol (5 min), 90\% alcohol (3 $\mathrm{min}$ ), $70 \%$ alcohol (3 minutes), running water (3 $\mathrm{min}$ ) and distilled water (1 $\mathrm{min})$.

Four staining were used in the histological analysis of the earthworm's body wall and anterior nervous structures. Details of these staining methods are described below. The Masson-Goldner trichrome (MGT) staining technique that identifies components of connective and muscle tissues selectively visualized by using a combination of three different staining solutions: Azophloxine and Tungstophosphoric acid Orange G solutions stain components such as muscle and cytoplasm, and Light green SF solution then is counter-stains connective tissue. A Sigma-Aldrich kit was used to perform this staining (catalog number: 100485). The Picrosirius red (PSR) staining technique is a developed simple and sensitive method that identifies fibrillar collagen networks in tissue sections. In humans, PSR staining associated with morphometric image analysis has been used for qualitative and quantitative characterization of collagen network alterations in degenerative pathologies and inherited or acquired diseases [26]. The PSR staining technique was performed as described by Wegner et al. [27] using a solution with $0.5 \mathrm{~g}$ of Direct Red 80 (2610-10-8; Sigma-Aldrich Corp., St. Louis, MO) in $500 \mathrm{~mL}$ of saturated picric acid (P6744-1GA; Sigma-Aldrich). After staining, all slides underwent standard dehydration, with three passes in anhydrous alcohol (5 min each) and one in xylene for assembly. To visualize the main cells that make up the neural structures of E. fetida, the anterior part of the earthworm was cut with a scalpel and the internal structures between the $1^{\text {st }}$ and $3^{\text {rd }}$ segments were removed with the aid of a brush wetted with phosphate buffer. These structures were then gently squeezed and spread out on a histological slide. After drying the slide, they were fixed and stained with a Panoptic kit and covered with a coverslip before analysis with an optical microscope. 


\section{Gene Expression protocol}

Coelomocytes and CNS samples were obtained from the first three metamers that contain the dorsal ganglion and pharynx and used to evaluate the impact of Rotenone on gene modulation. As the CNS of earthworms have a ring form it is not possible to isolate ganglion and pharynx tissues. The genes analyzed here were associated with immunocompetence and neural function. The ganglion was removed from the body cavity and macerated for evaluation of gene expression. The general qRT protocol used here is similar to previously described by Jung et al. [9]. Briefly, earthworms were rinsed with distilled water, dried, and ground with liquid nitrogen. For each replicate, RNA was obtained from, at least, three earthworms. The RNA was extracted using Quick-Zol (TriZol, Ludwig Biotech Co, Alvorada, Brazil), following the manufacturer's instructions, and quantified using the NanoDrop ${ }^{\mathrm{TM}} 1000$ spectrophotometer (Thermo Fisher Scientific, Waltham, MA, EUA). Further, RNA samples were treated with $0.2 \mu \mathrm{L}$ of Dnase (Invitrogen Life Technologies, Carlsbad, CA, USA) at $37^{\circ} \mathrm{C}$ for $5 \mathrm{~min}$, to digest any DNA contamination, and at $65^{\circ} \mathrm{C}$ for $10 \mathrm{~min}$. Gene expression was evaluated using qRT-PCR by using a thermocycler (Axygen ${ }^{\circledR}$ MaxyGene II Thermal Cycler, Corning Life Sciences, Tewksbury, MA, EUA). RNA was reverse transcribed to cDNA in the presence of $1 \mu \mathrm{L}$ of iScript reverse transcriptase and $4 \mu \mathrm{L}$ of iScript Mix (Bio-Rad Laboratories, Hercules, CA, EUA) using the following reaction steps: $25^{\circ} \mathrm{C}$ for $5 \mathrm{~min} ; 42^{\circ} \mathrm{C}$ for $30 \mathrm{~min} ; 8^{\circ} \mathrm{C}$ for $5 \mathrm{~min}$; and $5^{\circ} \mathrm{C}$ for 60 min. PCR analysis was conducted using $1 \mu \mathrm{L}$ of cDNA and $1 \times$ QuantiFast SYBR Green PCR Kit (Qiagen, Hilden, Germany). Each reaction was performed in a volume of $20 \mu \mathrm{L}$ containing $1 \mu \mathrm{L}$ of cDNA sample (1:20 dilution). The following cycling conditions were used to amplify both genes: $95^{\circ} \mathrm{C}$ for $5 \mathrm{~min}$, followed by 40 cycles of $95^{\circ} \mathrm{C}$ for $5 \mathrm{~s}$, and $63.5^{\circ} \mathrm{C}$ for $30 \mathrm{~s}$ (for COII, EaTLR, and nicotinic acetylcholine receptor $\alpha 5$ genes); $60^{\circ} \mathrm{C}$ for $30 \mathrm{~s}$ (for ND1 and SOX-4 genes); $64.2^{\circ} \mathrm{C}$ for $30 \mathrm{~s}$ (for CYTB gene), followed by a melting gradient from $50^{\circ} \mathrm{C}$ to $90^{\circ} \mathrm{C}\left(1^{\circ} \mathrm{C}\right.$ increment every $\left.5 \mathrm{~s}\right)$. Reactions were performed in duplicates and actin-1 (Y09623) was used as the housekeeping gene. After the reaction, amplification curves, melting curves, and the standard curve slope were checked to ensure that non-specific amplification did not occur. Relative quantification of 
Ct values was performed as described by Mo et al. [28]. The primers for genes evaluated here are detailed in Table 1.

Table 1 Genes evaluated in the coelomocytes and dorsal brain ganglia of Eisenia fetida earthworm chronically exposed to Rotenone (30 nM)

\section{Gene}

Main Functions

Primers

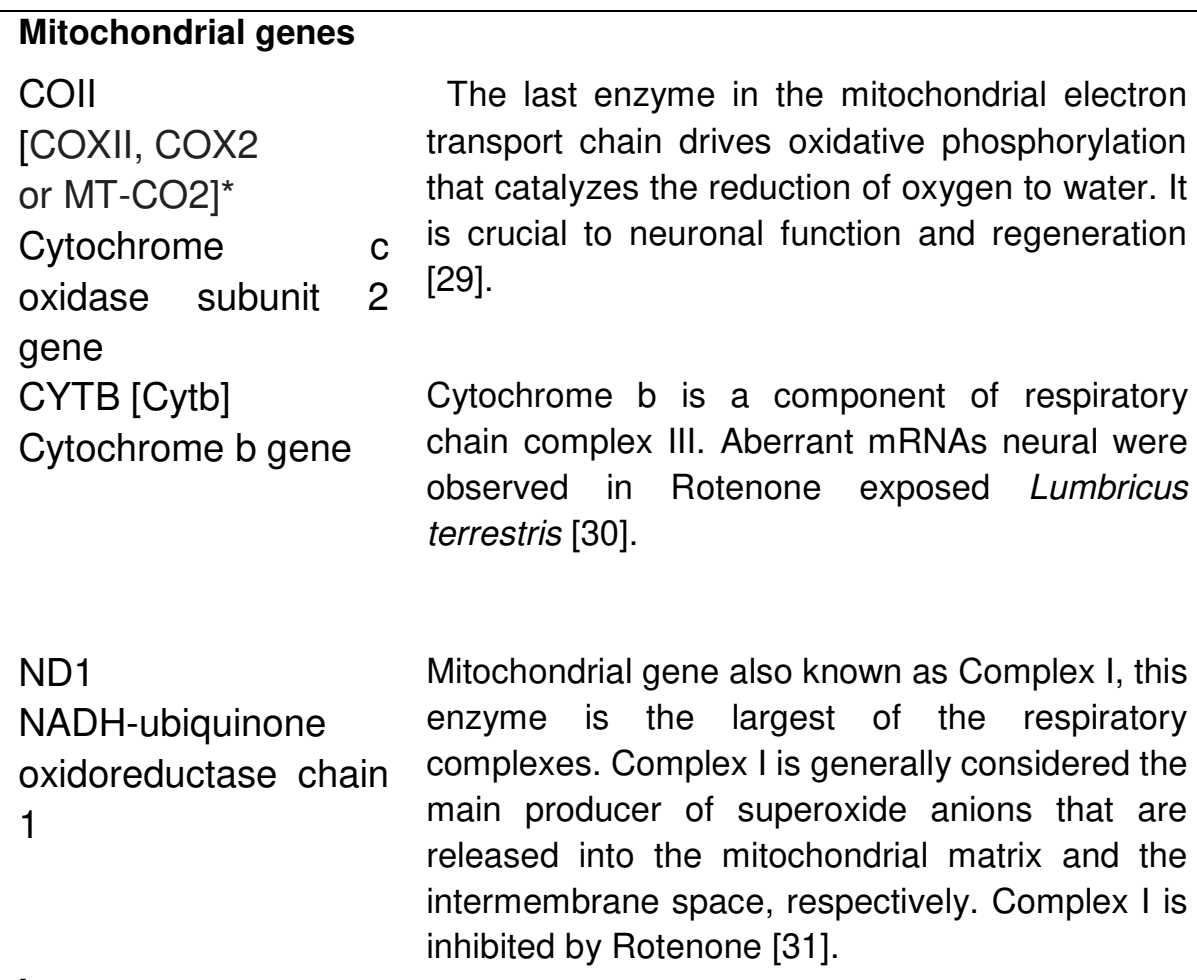

\section{Immunocompetent genes}

EaTLR

Toll-like receptor gene NCBI:

JX898685

AMP [Lumbricin 1]

Antimicrobial peptide

gene

AF060552

\section{Genes with activity in neuromuscular junctions}

ACHE

Acetylcholinesterase
Both genes are modulated by the presence of microorganisms and by tissue injury in earthworms [28] and by E.fetida acutely exposed to Rotenone [9].
It is an enzyme that catalyzes the breakdown

of acetylcholine and of some other choline esters
Forward

5'-CGGGGGACTATCGACT

CCTA-3';

Reverse

5'-GGCACGGCATCCACTTT

TAC-3'

\author{
Forward \\ 5'-GAGGGGCAATAGTAAT \\ CACAAA-3'; \\ Reverse \\ 5'-АAТССТССТСАAАTTC \\ ATTCAACAG-3' \\ Forward \\ 5'-GCCAGCTTTTGTCAG \\ GAGGA-3'; Reverse \\ 5'-GGGCAGAGTTCCCT \\ GTCATT-3'
}

Forward:

5'-GAGACATCGCTGAA

AACATC-3'; Reverse:

5'-CTGCATCTGAATCTG

GAGTC-3')

Forward:

5'-CATACTCGGAACGCA

AGAACC-3'; Reverse:

5'-TTTGATGACCTTCTG

CGGTG-3' that function as neurotransmitters found at mainly neuromuscular junctions and in chemical synapses of the cholinergic type. The ACHE expression is altered in $L$. terristris exposed to Rotenone [30].
Forward

5'-TGGCATTGTATCACC

CGGAA-3';

Reverse

5'-TGTTGAACCCAATC

AAGGGCT-3' 
nAChRs a5

Nicotinic

acetylcholine

receptors

\section{Housekeeping gene}

Actin-1
Receptor polypeptides that respond to the neurotransmitter acetylcholine. In the neuromuscular junction, nAChRs are the primary receptor in muscle for motor nerve-muscle communication that controls muscle contraction. In the peripheral nervous system, nAChRs receptors transmit outgoing signals from the presynaptic to the postsynaptic cells within the sympathetic and parasympathetic nervous systems. In the immune system, nAChRs regulate inflammatory processes and signal through distinct intracellular pathways. The nAChRs expression is altered in $L$. terristris exposed to Rotenone [30].

Reference gene in the qRT amplification
Forward

5'-CTTCTGCAGTGTCCTT

CGGT-3'; Reverse

5'-CGAGTCCGACCTTGA

GAACC- $3^{\prime \prime}$
Forward

5'-TACGCCAACACC

GTTCTCTC-3';

Reverse

5 -

TTTTCATCGTCGGTGGAGCA$3^{\prime}$

${ }^{*}$ [ ] contains other abbreviations for the same gene

\section{Statistical analysis}

Graphics and statistical comparisons between control and Rotenone treatments were performed by Student T test using GraphPad Prism software (version 8.02, 2019). The data in graphics were presented as the mean plus and standard deviation (SD). Two-way analysis of variance followed by post hoc Bonferroni test was performed in comparisons involving temporal variations of the analyzes on the $1^{\text {st }}, 7^{\text {th }}$, and $14^{\text {th }}$ day of treatment and comparisons between control and Rotenone earthworms. Comparisons performed only on the $14^{\text {th }}$ day of treatment were made using One-way variance analysis followed by Tukey's post hoc test. Cyto-histological analysis was performed using the Digimizer image analysis software package (version 5.4.1, MedCalc Software, Belgium), which allowed manual measurements, as well as automatic object detection, for the measurement of object characteristics. All tests with a $p \leq 0.05$ were considered statistically significant. 


\section{Results}

As expected, during the exposure to Rotenone, earthworms were frequently found outside the ground or on the container wall indicating that this molecule is aversive to earthworms (Fig. 2 A, B). However, it was not possible to quantify this observation, as the pattern changes over time and days. Next, the behavior of escape to boric acid on the $1^{\text {st }}, 7^{\text {th }}$, and $14^{\text {th }}$ day after exposure to Rotenone was analyzed. As can be seen in Fig. 1C, 100\% of the controls migrated to the side of the soil not boric acid contaminated. The same pattern was also observed in one-day earthworms exposed to Rotenone. However, the rate of choice for good quality land dropped significantly, especially after 14 days of exposure to Rotenone. As the worms are placed in the middle of the container and they can choose, these results indicated a loss of sensitivity to other contaminant agents.

From the extrusion of coelomic fluid, it was possible to detect whether Rotenone would be stimulating the proliferation of coelomocytes, which is a primary event in the induction of pro-inflammatory states. The results showed a higher frequency of immune cells in S and G2 phases in earthworms treated with Rotenone $(38.0 \pm 1.6 \%)$ than in control earthworms $(22.3 \pm 1.9 \%)(p<0.01)$ after 24 hours of treatment (Fig. 2D). Analysis of mitotic frequency modulation throughout treatment showed a decrease in the proliferation rate on the $14^{\text {th }}$ day both in controls and in earthworms treated with Rotenone. However, the frequency of cells in S and G2 phases remained higher in earthworms Rotenoneexposed than in controls (Fig. 2E). 


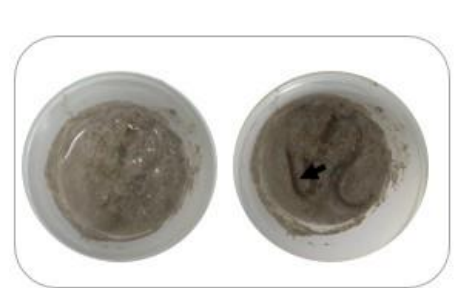

A
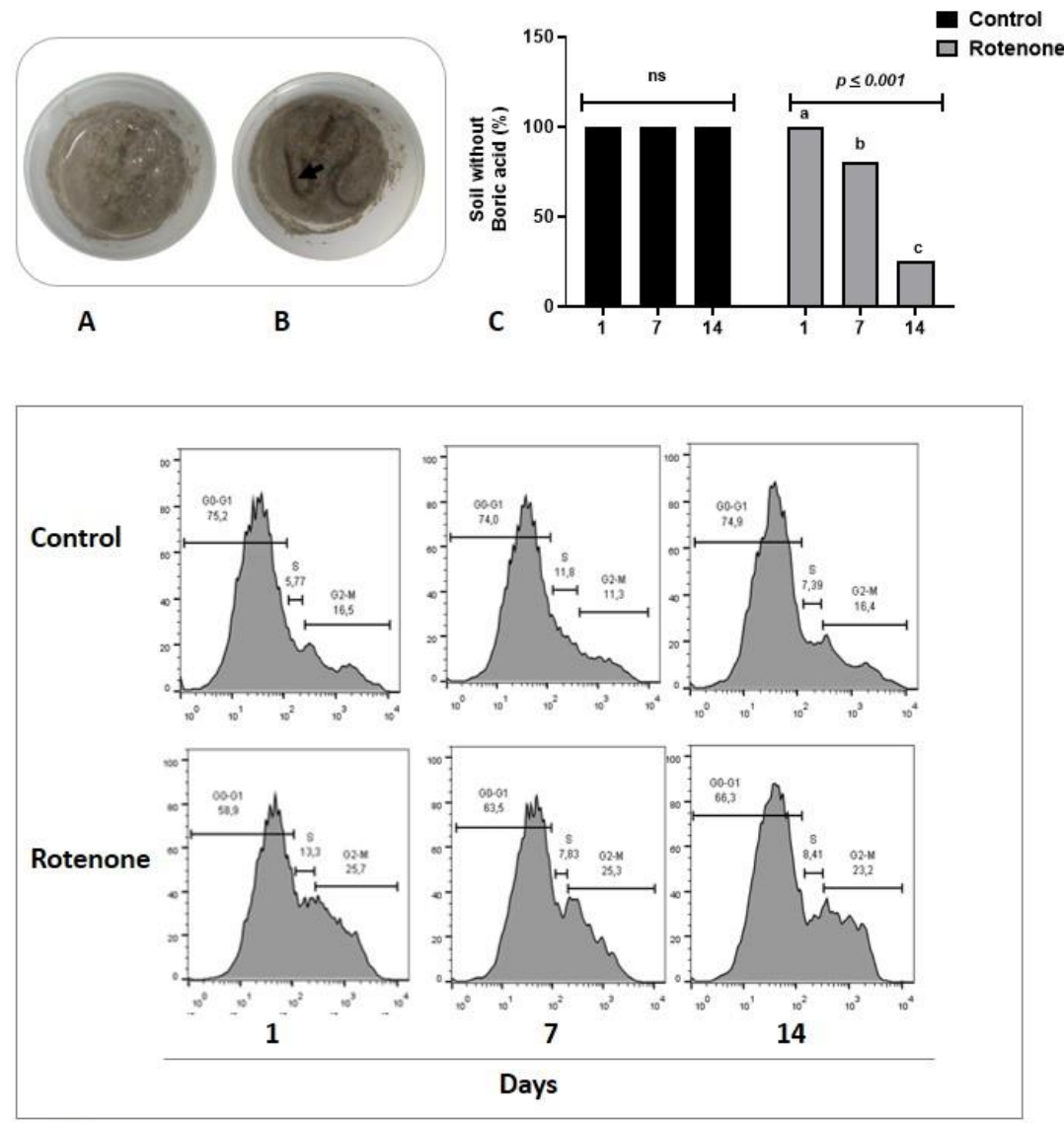

D

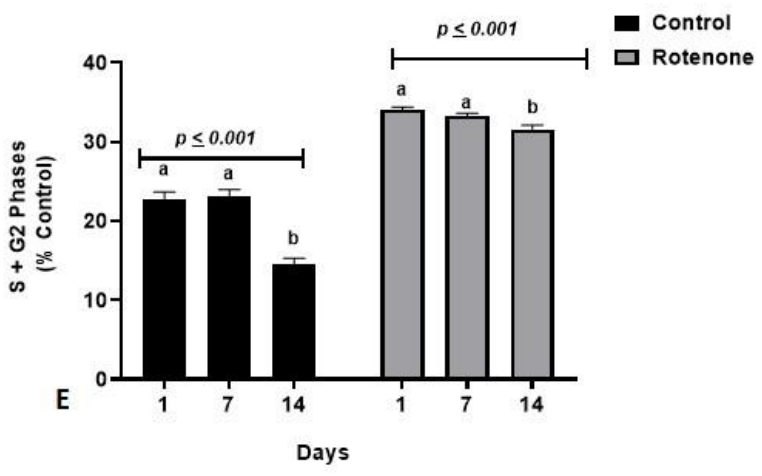

Fig. 2: Photograph of the culture vessel with artificial medium without Rotenone. A and with Rotenone $(30 \mathrm{nM})$. B Rotenone-treated earthworms tended to remain on the surface of the middle or wall of the container rather than burrowing in as with control earthworms. C Boric acid escape test showing the frequency of earthworms that chose to migrate to good quality soil on the $1^{\text {st }}, 7^{\text {th }}$, and $14^{\text {th }}$ day of treatment. D representation of the cell cycle (phases G1, S, and G2) of total coelomocytes obtained via coelomic fluid extrusion on the $1^{\text {st }}, 7^{\text {th }}$, and $14^{\text {th }}$ day of treatment. E The cell proliferation pattern was evaluated by the sum of S-phase cells, which are duplicating their DNA for further mitosis, and G2-phase cells that are already preparing to divide. Samples from both the boric acid escape test and the mitotic pattern were compared by two-way analysis of variance followed by Bonferroni's post doc test. Different letters indicate statistical differences $(p<0.05)$ between the samples being compared. Representative flow cytometry of $1^{\text {st }}, 7^{\text {th }}$, and $14^{\text {th }}$ days after starting treatment with Rotenone (Ro, $30 \mathrm{nM}$ ) in comparison with no-treat earthworms (control $=\mathrm{Co}$ ). 
The coelomocytes distribution in amoebocytes and eleocytes was also compared between earthworms treated and untreated with Rotenone (Fig. 3A, B). On the first day after the start of treatment, a significant increase in amoebocytes was observed in earthworms exposed to Rotenone (37.1 $\pm 1.2 \%)$ than controls $(13.0 \pm 0.5 \%)(p \leq 0.001)$. However, it was also observed that Rotenone exerted a significant suppressive effect on the number of eleocytes $(6.1 \pm 0.8 \%)$ in comparison to controls $(11.6 \pm 0.9 \%)(p \leq 0.001)$. However, in the longitudinal analysis, while in controls the levels of amoebocytes were similar on the $7^{\text {th }}$ and $14^{\text {th }}$ day, in earthworms reared with Rotenone the frequency of eleocytes dropped significantly (Fig. 3B). After 14 days of treatment, the frequency of eleocytes rose significantly in earthworms exposed to Rotenone. Even so, when compared to the control group $(13.5 \pm 0.9 \%)$ this frequency was significantly low $(7.6 \pm 0.8 \%)$. Microscopic analysis of the coelomic fluid showed that the autofluorescence of eleocytes was less intense in earthworms exposed to Rotenone than in controls (Fig. $3 \mathrm{C}$ ). The production of NETs from coelomocytes exposure to dead yeasts also indicated a lower efficiency of this process in samples from earthworms exposed to Rotenone than control earthworms (Fig. 3D).

The effect on cell expression of earthworm cells treated for 14 days with Rotenone was also evaluated using cells from celomic fluid and from the first three anterior segments of earthworms where is located the earthworm's CNS. Data from the celomic fluid are synthesized in Fig. 3E. Rotenone induced downregulation in the mitochondrial NDI and CYTB genes but had no significant effect on the COIl gene expression. On the other hand, Rotenone triggered significant overexpression of the EaTLR gene and downregulation in the AMP, both genes associated with immune function. Coelomocytes from earthworms treated with Rotenone also showed downregulation of nAChRs a5 and Ache genes. The analysis of gene expression using tissues from the first three anterior segments where the dorsal neural ganglion is located was quite difficult. 


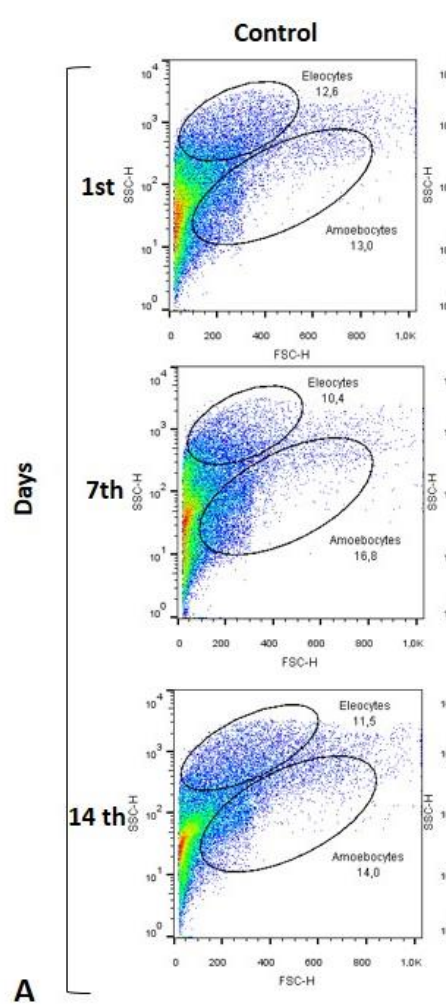

A

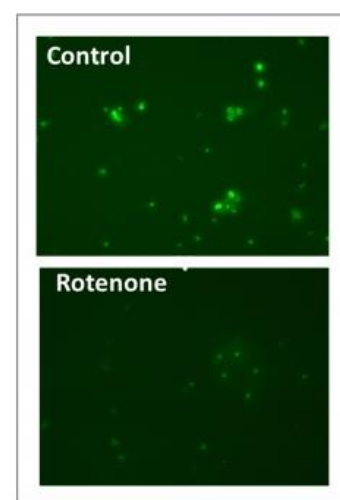

C
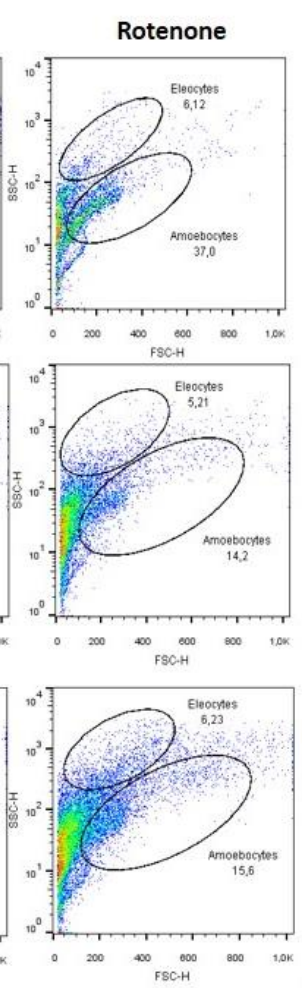

B
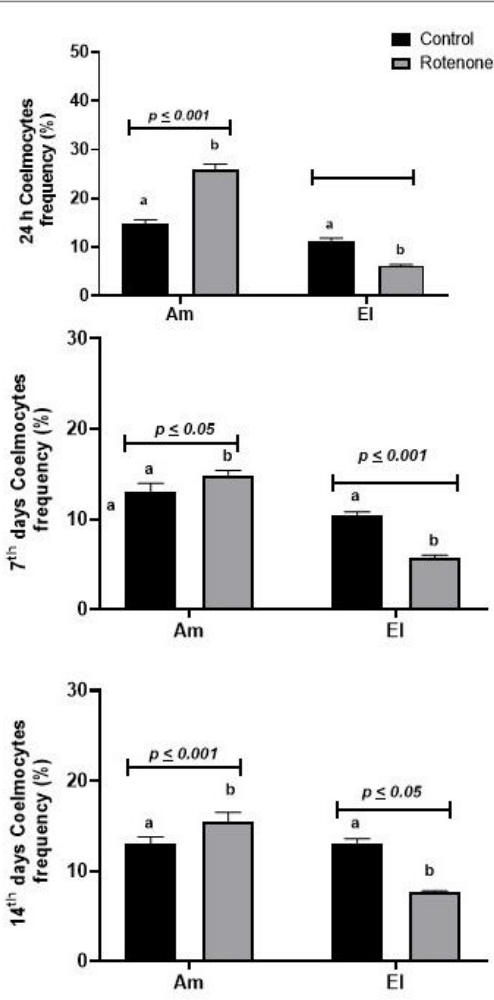

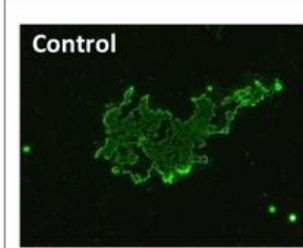

Rotenone

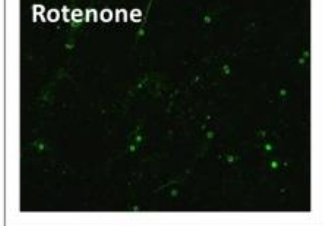

D

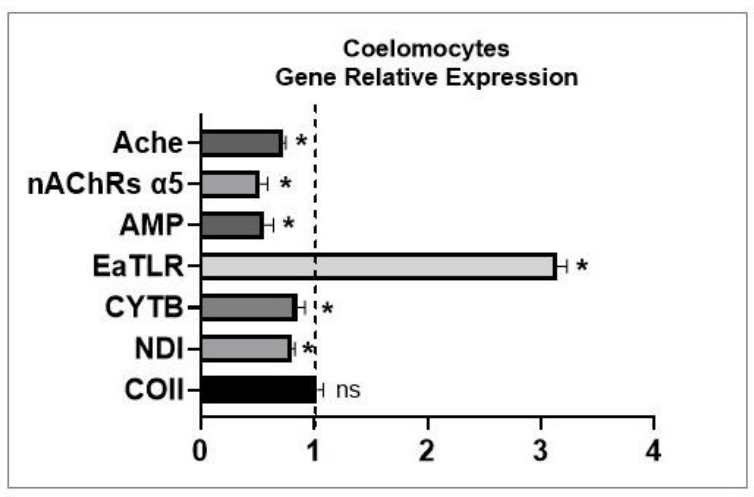

E

Fig. 3: Comparison between immunocompetence markers between earthworms' Rotenone (30 $\mathrm{nM}$ ) exposed and controls. A Graphic representation of the flow cytometry showing the distribution of coelomocytes in amoebocytes $(\mathrm{Am})$ and eleocytes $(\mathrm{EI})$ on the $1^{\text {st }}, 7^{\text {th }}$, and $14^{\text {th }}$ day of treatment in an artificial culture medium. B Comparison of coelomocytes distribution via One-way analysis of variance followed by Tukey's post hoc test. Statistical differences with $p<0.05$ are identified by different letters. $\mathbf{C}$ graphic representation of the autofluorescence of eleocytes obtained from coelomic fluid of earthworms with and without exposure to Rotenone. D graphic representation of the ex vivo production of extracellular neutrophils traps (NETs) stimulated by the presence of dead yeasts. NETs were detected by the presence of double-stranded DNA that binds to the fluorescent dye DNA Picogreen. E Rotenone effect on the coelomocyte's gene relative expression of mitochondrial genes (COII, NDI, CYTB), immune function (EaTLR), and neurotransmissions (nAchRsa5 and Ache). Values are normalized by the Actin-1 gene and represent their value expressed concerning the control with reference value 1 (dashed line in the graph). 
Only two genes (COIl and nAChRs) amplified in tissues from three anterior segments where is located earthworm cerebral ganglion. Similar to observed in the coelomocytes, the expression of the COll gene from earthworms chronically exposed to Rotenone was the same as in controls. However, an antagonist effect of Rotenone on the nAChRs gene was observed, since at contrary to coelomocytes from samples Rotenone exposed its gene was significantly overexpressed $(6.05 \pm 0.08)$ than controls $(p \leq 0.001)$.

After 14 days, changes in the VGN and cell wall structures were evaluated and compared between control and earthworms chronically exposed to Rotenone. Fig. 4 presents a synthesis of the main histological structures investigated from microphotographs obtained from control earthworms, whereas Fig. 5 highlights the main alterations produced by Rotenone in earthworms. Chronic exposure to Rotenone induced a significant increase in cell wall thickness with an increase in collagen deposition observed via Picrosirius staining (Fig. E, F). An extensive area of brown-dark pigment was also observed in the circular muscle layer of earthworms exposed to Rotenone than controls (Fig. $5 \mathrm{H}$ ). In some samples, it was also possible to detect some disarrangements in the longitudinal muscle fibers and a higher number of glandular cells in the epidermis. However, there were no uniform changes in all analyzed samples.

The main changes in VNG induced by chronic earthworm exposure to Rotenone were: (1) TL enlargement with greater collagen deposition than controls (Fig. 5L); (2) infiltration of some muscle cells present in the TL into the ganglion, mainly in spaces occupied by giant neural bodies (Fig. 5M) and (3) presence of degenerated areas in the neuropil (Fig. $5 \mathrm{~L}$ ). 

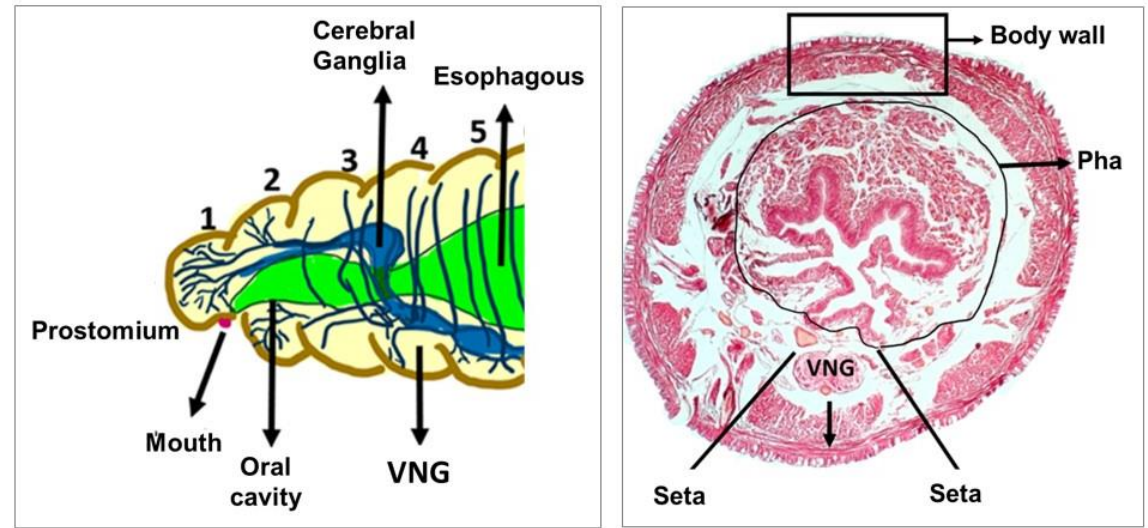

A

B
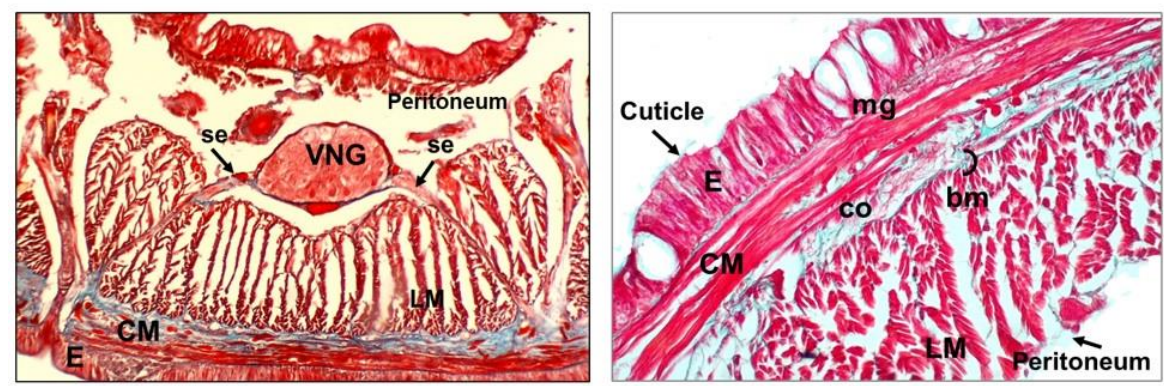

C

D
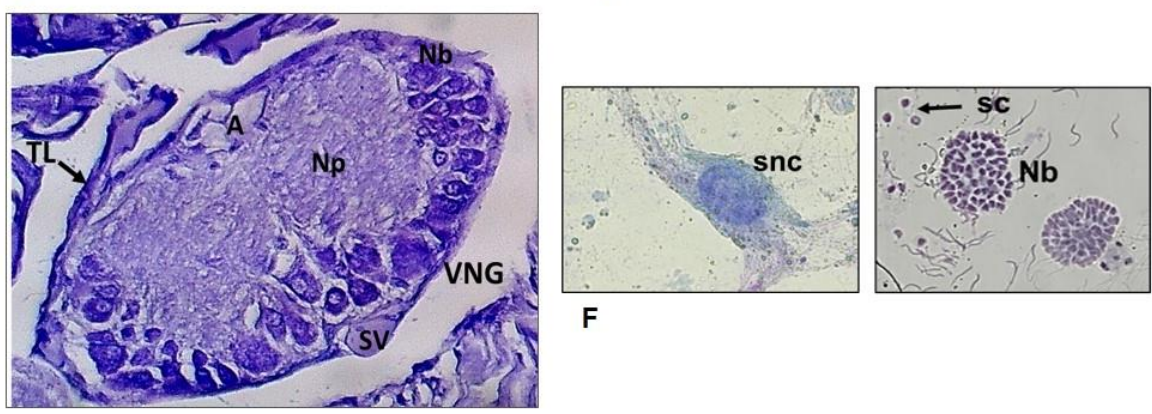

$\mathbf{F}$

E

Fig. 4. Anatomical and histological characteristics of Eisenia fetida analyzed by optical microscopy stained with Masson-Goldner dye. (A) General scheme of the main anatomical structures observed in the first three metamers of the earthworm. $V N G=$ ventral nervous ganglia. (B) General view of histological cross-section (Magnification $10 \mathrm{x}$ ); Pha: pharynx. (C) VNG and body wall interaction (20x Magnification): $\mathrm{E}=$ epidermis; $\mathrm{CM}=$ circular muscle layer; $\mathrm{LM}=$ longitudinal muscle layer; $\mathrm{se}=$ segmental nerve. $(\mathrm{D})$ Detail of the body wall (Magnification 40x): $\mathrm{mg}=$ mucous gland; $\mathrm{CO}=$ collagen stained in the blue-green present in the extracellular matrix CM-associated. (E) VNG structures stained with Crystal violet dye: $T L=$ trilaminar sheath composed by peritoneum, muscle cells and collagenous fibrous sheath; $A=$ dorsal/lateral giant axons; $S V=$ sub neural blood vessel $\mathrm{Np}=$ neuropil. $(\mathrm{F})$ details of cells present in VNG obtained from smears and spreads with a swab stained with Panoptic kit dye (magnification 40x): $\mathrm{snc}=$ cell bodies of sensorial enlarged neurons $\mathrm{sc}=$ satellite cells of the neuroglia; $\mathrm{Nb}=$ giant neurons with extensive Nissl bodies. 


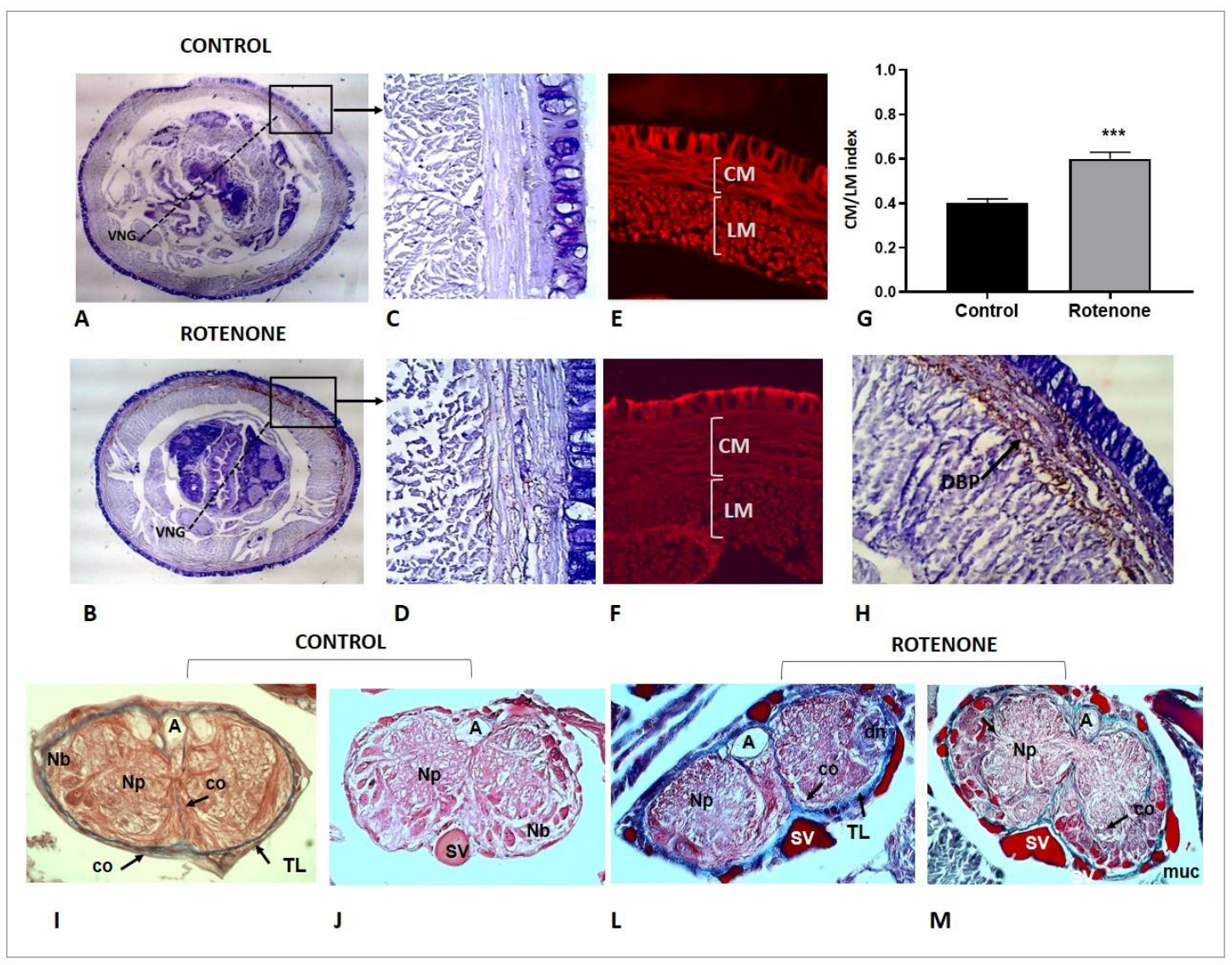

Fig. 5: Histological alterations triggered by chronic Rotenone (30 $\mathrm{nM})$ exposure in Eisenia fetida analyzed by optical microscopy. The square in microphotographs (A) and (B) indicates where the body wall was analyzed. Microphotographs (C) and (D) show enlargement of the circular (CM) and longitudinal muscle (LM) layers in earthworms exposed to Rotenone. The enlargement of muscle layers was associated with a greater deposit of extracellular matrix rich in collagen and an apparent decrease in the number of muscle fibers $(E)$ and $(F)$. An extensive deposit of dark brown pigments (DBP) in the circular muscle layer was observed in earthworms exposed to Rotenone (H). Microphotographs from (I) to (M) represents the Ventral Neuron Ganglia (VGN) histological structures: $\mathrm{A}=$ dorsal and/or lateral giant axons; $\mathrm{Nb}=$ neuron bodies; $\mathrm{Np}=$ neuropil; $\mathrm{CO}=$ extracellular matrix with collagen stained in blue-green color; $T L=$ trilaminar sheath composed by peritoneum, muscle cells, and collagenous fibrous sheath; muc= muscular cells of TL structure stained in red by Mason-Goldner dye, which also blushes red blood vessels, such as subneural blood vessel (SV). VGN from Rotenone-exposed earthworms showed TL enlargement (L, M) than controls $(\mathbf{I}, \mathbf{J})$ with greater collagen deposition (microphotograph $\mathbf{L}$ ) and infiltration of muscle cells (muc) into the area where $\mathrm{Nb}$ and $\mathrm{Np}$ are located (microphotograph M). Compared to the VGN of controls, the amount of giant sensory neurons appears to have decreased in earthworms exposed to Rotenone. Magnification $40 \mathrm{x}$.

\section{Discussion}

The present study evaluated the impact of superoxide imbalance triggered by chronic Rotenone exposure on earthworms. The whole results indicated behavioral and immune modifications suggesting that mitochondrial dysfunction could have an evolutionarily conserved impact on alterations triggered by chronic 
stress exposure. These results can be considered relevant since existing evidence that superoxide imbalance could contribute to greater sensibility to stressful events associated with the development of mood disorders by induction of chronic inflammatory states [8]. Next, we will discuss the main aspects related to the study and the results observed here, starting with the use of Rotenone as a pharmacological model for the induction of mitochondrial dysfunction.

The Rotenone has been consistently used in experimental models involving mitochondrial dysfunction of neurodegenerative morbidities, especially Parkinson's disease [15]. This molecule can inhibit mitochondrial complex I of oxidative phosphorylation interrupting mitochondrial electron transport [14]. As mitochondrial dysfunction has been associated with the etiopathology of psychiatric disorders, Rotenone has also been used in experimental in vitro protocols related to these diseases [32, 33]. Furthermore, some experimental investigations also used Rotenone as an inductor of depressive-like symptoms in rodents [34-36].

As constant exposure to Rotenone can cause extensive neurodegeneration, which was not our primary concern, we structured a protocol that sought to mimic stressful situations experienced by humans and other vertebrate animals that have to return to a given stressful environment, for survival reasons. It is possible to infer that this prospect of the worm moving away and returning to the environment increased its survival rate from exposure to Rotenone. Since exposure to Rotenone affected survival behavior against exposure to boric acid and also created alterations in immune metabolism, we estimated that earthworms could be used as a potential experimental model for studies involving chronic stress, inflammation, and behavior. In other words, studies in earthworms could be an alternative or complementary experimental model to the in vitro and rodent protocols that are currently performed and that involve mitochondrial dysfunction and mood-like behaviors. In this case, it would be interesting for further studies to evaluate the possibility of developing a protocol in earthworms that is similar to CUMS (chronic unpredictable mild stress) since currently CUMS are the most common and effective rodent model of depression [37].

In the protocol developed here, we allow the earthworms to be freely exposed to the culture medium containing Rotenone, which is a major source of 
stress considering the standard condition of these animals. Perhaps this fact has contributed to attenuate the toxic effect on survival and parkinsonian alterations that could occur by Rotenone exposure as described by Subaraja and Vanisree [30] in Lumbricus terristris. In these animals, Rotenone had a degenerative impact on giant fibers affecting neuronal behaviors/locomotion of worms. Despite the neural alterations histologically observed in earthworms, they were not sufficient to induce neurodegenerative processes similar to Parkinson's, which would impact the locomotion and survival of earthworms. This statement is based on the fact that, in the behavior of escaping boric acid, all earthworms chose a soil to migrate either the good quality soil or the soil contaminated with the aversive agent.

However, alterations in the cell wall were observed, including an increase in the deposit of dark brown pigments and enlargement of the circular and longitudinal muscle layers, as well as enlargement of the capsule that delimits the VNG and acts as a barrier between the earthworm's CNS and the coelom cavity. These histological changes suggest that they are an adaptive response of the earthworm in an attempt to protect it against the negative effects of Rotenone.

Since the earthworm has a close interaction between its skin and the environment, the deposition of dark brown pigments in the circular muscle layer may be a consequence of direct contact with Rotenone. However, whether these alterations represent an effort to protect the interior of the body from the action of Rotenone, or whether they represent residues produced by toxicity to this molecule is an open question. Unfortunately, investigations describing the production of dark brown pigments in earthworm tissues by exposure to chemical agents are still incipient. A study that can be highlighted was the one conducted by Eseigbe et al. [38] in the earthworm Eudrilus eugeniae earthworms, exposed to sublethal concentrations of benzene, toluene, and xylene for 28 days. Authors reported that these chemicals induced pathological changes including dark brown pigments in the clitella tissues. Another study where E. fetida were exposed to different concentrations of crude oil contaminated soils for 14 days described severe disruption in the arrangement of their body wall muscle layers, cellular degeneration, and deposition of dark pigments [39]. These studies reinforce the idea that, in situations of chronic exposure to xenobiotics, there is a deposition of dark brown pigments, which can be a protection strategy against their toxicity. 
Although we were unable to identify similar studies involving analysis of histological changes in the VNG, the enlargement of the surrounding ganglion capsule also indicates a protective strategy against Rotenone.

Moreover, to the cell wall and VGN alterations, a significant increase in the expression of the nAChR alpha5 gene was observed in structures of anterior segments where is located dorsal and ventral neural ganglia of earthworms Rotenone exposed. This gene belongs to the superfamily of ligand-gated ion channels that are widely expressed throughout the CNS and peripheral nervous systems playing important roles in modulating a wide range of higher cognitive functions in mammals. Some evidence suggested that $\mathrm{nAChR}$ expression could trigger dopamine release and has a protective effect against neurodegeneration associated with Parkinson's and Alzheimer's diseases [40]. As one of the main consequences of exposure to Rotenone is the degeneration of dopaminergic neurons, the increase in gene expression could represent an attempt to mitigate the negative impact of mitochondrial dysfunction in earthworms.

Certainly, an important impact related to chronic Rotenone exposure was on the immune metabolism of earthworms. To interpret these changes, it is necessary to comment that earthworms defend themselves from the predators attacked, pathogens, and chemical toxicants expelling out of the body a large quantity of coelomic fluid [41]. As the earthworm lives in the soil, it is exposed to several situations involving coelomic extrusion. Consequently, the efficient recovery of coelomocytes and soluble factors after stress-related disturbance is adaptive. However, in a phase of chronic exposure to stressors such as Rotenone, the reconstitution of coelomic fluid can be an important physiological challenge.

This is perhaps the reason why we found an imbalance in the proliferation rate and in the types of coelomocytes that were produced by earthworms exposed to Rotenone when compared to controls. The results described here showed a significant decrease in the number of eleocytes in earthworms exposed to Rotenone. The drop in the frequency of eleocytes as well as the autofluorescence associated with the riboflavin storage inside these cells may be associated with the continued extrusion of coelomic fluid by the earthworm during exposure to Rotenone, as a strategy to reduce its toxicity. The chloragocytederived eleocytes characteristically express autofluorescence emanating mainly 
from riboflavin (vitamin B2), which is a major fluorophore in E. fetida coelomocytes [21]. In addition, the investigation conducted by Santocki et al. [42] estimates that depleted riboflavin from eleocytes is fully restored only after 3,5 weeks post-extrusion.

Similar to vertebrate leukocytes (e.g., neutrophils), coelomocytes are responsible for many immune functions like phagocytosis, cytotoxicity, and secretion of humoral factors. These cells are also able to produce NETs in the presence of large microorganisms and substances [13]. Here it was also observed that chronic exposure to Rotenone caused a decrease in the ex vivo formation of NETs via exposure to dead yeasts. Problems in the formation of NETs and also of brown bodies (BBs) which are structures formed by coelomocytes, NETs, microorganisms, and/or undesirable substances have been described in earthworms acutely exposed to Rotenone [9]. On contrary, previous studies, such as performed by Alves et al. [18] showed that antioxidant and antiinflammatory caffeinated extracts increased the efficiency of ex vivo NET production in the presence of dead yeasts. As the frequency of amoebocytes does not decrease significantly in exposure to rotenone on 7th and 14th when it compared to itself, it is possible to infer that this molecule produces some level of inhibition in the formation of NETs which could mean a decrease in the immunocompetence of earthworms.

This suggestion is supported by the result showing downregulation of the AMP lubricin 1 gene, which plays a relevant role in the earthworm's immune response to microorganisms. However, contrary to that reported by Jung et al. [9] in the acute exposure, after 14 days EaTLR gene was significantly overexpressed in earthworms' Rotenone exposed. Toll-like receptors (TLRs) are well conserved in several animal groups as a crucial pattern recognition receptor (PRRs) involved in the recognition of pathogen-associated molecular patterns (PAMPs) and in recognition of various damage/danger-associated molecular patterns (DAMPs) intrinsically generated [43]. Therefore, the overexpression of the EaTLR gene by earthworms chronically Rotenone exposed could indicate inflammatory patterns triggered by tissue injury.

Despite their primitive brain ganglion CNS, these animals are very sensitive to environmental physicochemical properties which directly or indirectly influence the availability of resources for earthworm survival [44]. 
A previous study showed that $E$. fetida acutely exposed to Rotenone also presented relevant immune impairment and behavioral alterations [9]. It is worth noting that the exposure of neural cells to Rotenone has been used as an experimental model to understand the role of mitochondrial dysfunction related to mood disorders. Based on these results, we developed a chronic stress protocol in which $E$. fetida were exposed to Rotenone for 14 days which allowed us to assess its impact on the immune and neural systems of earthworms. Finally, it is important to highlight that Rotenone-induced downregulation of genes related to mitochondrial function, which we would expect to be overexpressed in an attempt to mitigate the negative impact of this molecule. However, it is possible that the inhibition of complex I by Rotenone, which ends up decreasing the efficiency of ATP production and increasing the concentration of ROS, is not enough to induce positive genomic feedback related to the expression of enzymes that are part of the oxidative phosphorylation.

From these results, it is important to consider that in evolutionary terms, the animal stress response is highly adaptive, in facing dangerous variables related to competitors, predators, or pathogens [45]. Biologically, the stress response involves relevant biochemical, cellular, and physiological changes, mobilizing a large amount of energy generated by mitochondria allowing the animal to flee or fight. Furthermore, the stress response creates a short window of immune suppression that allows the body to deal with a stressful situation [46, 47]. However, this adaptive situation triggered by the presence of acute stress reverts to a non-adaptive condition involving alterations that can be found in animals with primitive CNS such as earthworms.

Furthermore, there could be biochemical-molecular patterns that trigger a greater sensitivity to chronic stress present in complex organisms such as humans, as well as primitive ones such as earthworms. This could be the case of the unbalance of the superoxide anion caused by genetic and/or environmental factors.

Even though some considerations can be interpreted as speculative, our results reinforce the link between stress and chronic inflammation via the occurrence of the following events:

(1) in face of stressful situation animals generates greater energy expenditure associated with the fight or flight behaviors. 
(2) the increase in ATP synthesis by mitochondria triggered by a chronic stressor event is accompanied by an elevation in the superoxide levels and other ROS molecules.

(3) as the adaptive response to a stressor is acute and not persistent, the occurrence of chronic stressful events does not induce a compensatory antioxidant reaction to control the increase of ROS levels into the cells.

(4) this leads to the establishment of an oxidative stress state inducing extensive macromolecules oxidation (lipids, proteins, and nucleic acids) affecting structural and cellular functions.

(5) DNA damage caused by oxidative stress, induces an increase in tissue apoptosis rates, contributing to a greater accumulation of metabolic residues in the extracellular matrix.

(6) Among cellular functions, that are also negatively affected by oxidative stress is autophagy, which is responsible for the efficient clearance of metabolic residues inside cells contributing to immune innate activation [48].

(7) finally, the accumulation of intra and intercellular metabolic DAMPs residues produces an inflammatory activation of macrophages and granulocytes in vertebrates. In primitive earthworms, coelomocytes activation by acute Rotenone exposure showed an increase in cellular proliferation, a high proportion of amoebocytes, and overexpression of AMP and EaTLR genes related to the inflammatory response, and inefficiency in the NETs productions in face of microorganism exposure [9].

(8) However, when the exposure to stressful events persists, there is no resolution of the activation response of immune cells leading to the establishment of a chronic inflammatory state that will act directly on the organism's neural and behavioral function; In the case of the earthworms investigated here, chronic exposure to Rotenone led to higher coelomocytes proliferation rates, followed by an antagonistic expression of the AMP and EaTLR genes, that indicate a decreasing in the immunocompetence of these organisms;

(9) The chronic inflammatory state, in turn, decreases the efficiency of the immune response, potentially increasing the susceptibility to pathogens, decreasing healing and regeneration processes, and detoxification to xenobiotics; 
(10) The chronic inflammatory pattern also affects neural function leading to behavioral alterations that impact negatively animal survival. However, the impact of chronic stress is not uniform among organisms of the same species, indicating that genetic or environmental factors can increase or decrease the organism's susceptibility to the negative effects of this condition.

(11) All these events can be modulating by pre-existing genetic or environmental factors that induce mitochondrial dysfunction and/or superoxide anion imbalance or help to alleviate these dysfunctions. For example, previous investigations carried out by our research team showed that Rotenone-induced mitochondrial dysfunction could be reversed in the presence of açai extract, an Amazon fruit with antioxidant and anti-inflammatory action [33]. Likewise, açai was able to reverse the inflammatory activation of macrophages [49] and microglia [50]. Other studies have also shown that the inflammatory pattern associated with the VV-SOD2 genotype was attenuated in vitro by supplementing cell cultures with lithium [51]. On the other hand, genetic variations leading to mitochondrial dysfunction could also contribute to the risk of mood disorders [52 $-54]$.

(12) Therefore, there existing genetic and environmental factors that could act as "neuro-inflammatory enhancers" decreasing the resilience resistance and resilience to chronic stressful events by differential modulation of mitochondrial function, mainly involved with the imbalance of superoxide anion and other ROS molecules.

\section{Conclusions}

Previous evidence suggested that exposure to chronic stressful events triggers chronic inflammatory processes leading to neural and behavioral dysfunctions associated with mood disorders development. On the other hand, there is also evidence that previous pro-inflammatory states, associated with genetic or environmental factors, could decrease resistance and resilience to chronic stress, contributing to the development of these psychiatric disorders. It is possible to infer that superoxide imbalance triggered by hyperactivation, or mitochondrial dysfunction is an evolutionarily conserved component in the progression of inflammatory sterile states and behavioral alterations related to 
exposure to chronic stress. The results described here, which were obtained from the chronic exposure of earthworms to Rotenone, corroborate this hypothesis. Further investigations are needed to assess the chronic exposure of earthworms to physicochemical stressors, without the presence of Rotenone.

\section{References}

1. WHO: World Health Organization Depression. https://www.who.int/newsroom/fact-sheets/detail/depression (2020), Accessed 3 Aug 2021.

2. Beurel E, Toups M, Nemeroff CB. The Bidirectional Relationship of Depression and Inflammation: Double Trouble. Neuron. 2020; doi: 10.1016/j.neuron.2020.06.002.

3. Bauer ME, Teixeira AL. Inflammation in psychiatric disorders: What comes first? Ann N Y Acad Sci. 2019; doi: 10.1111/nyas.13712.

4. Montano MAE, da Cruz IBM, Duarte MMMF, Krewer C da C, da Rocha MIDUM, Mânica-Cattani MF, et al. Inflammatory cytokines in vitro production are associated with Ala16Val superoxide dismutase gene polymorphism of peripheral blood mononuclear cells. Cytokine. 2012; doi: 10.1016/j.cyto.2012.05.022.

5. Barbisan F, Azzolin VF, Ribeiro EE, Duarte MMMF, da Cruz IBM. The In Vitro Influence of a Genetic Superoxide-Hydrogen Peroxide Imbalance on Immunosenescence. Rejuvenation Res. 2017; doi: 10.1089/rej.2016.1892.

6. Gałecki P, Śmigielski J, Florkowski A, Bobińska K, Pietras T, Szemraj J. Analysis of two polymorphisms of the manganese superoxide dismutase gene (Ile-58Thr and Ala-9Val) in patients with recurrent depressive disorder. Psychiatry Res. 2010; doi: 10.1016/j.psychres.2009.06.016.

7. Pietras T, Witusik A, Panek M, Gałecki P, Szemraj J, Górski P. [Anxiety, depression and polymorphism of the gene encoding superoxide dismutase in patients with chronic obstructive pulmonary disease]. Pol Merkur Lekarski. 2010;29(171):165-8.

8. Jung IEDC, da Cruz IBM, Barbisan F, Trott A, Houenou LJ, Turra BO, et al. Superoxide imbalance triggered by Val16Ala-SOD2 polymorphism increases the risk of depression and self-reported psychological stress in free-living elderly people. Mol Genet Genomic Med. 2020; doi: 10.1002/mgg3.1080.

9. Jung IEDC, Assmann CE, Mastella MH, Barbisan F, Ruaro RAS, Roggia I, et al. Superoxide-anion triggers impairments of immune efficiency and 
stress response behaviors of Eisenia fetida earthworms. Chemosphere. 2021; doi: 10.1016/j.chemosphere.2020.128712.

10. Princz J, Becker L, Scheffczyk A, Stephenson G, Scroggins R, Moser T, et al. Ecotoxicity of boric acid in standard laboratory tests with plants and soil organisms. Ecotoxicology [Internet]. 2017; doi: 10.1007/s10646-0171789-0.

11. Nakashima T, Mushiake H, Sakamoto K. Earthworm individualities when facing a conflict between turn alternation and aversive learning. Biophys Physicobiol. 2018; doi:10.2142/biophysico.15.0_159.

12. Engelmann $P$, Hayashi $Y$, Bodó $K$, Ernszt $D$, Somogyi I, Steib $A$, et al. Phenotypic and functional characterization of earthworm coelomocyte subsets: Linking light scatter-based cell typing and imaging of the sorted populations. Dev Comp Immunol. 2016; doi: 10.1016/j.dci.2016.06.017.

13. Homa J. Earthworm coelomocyte extracellular traps: structural and functional similarities with neutrophil NETs. Cell Tissue Res. 2018; doi: 10.1007/s00441-018-2787-0.

14. Xiong N, Long X, Xiong J, Jia M, Chen C, Huang J, et al. Mitochondrial complex I inhibitor rotenone-induced toxicity and its potential mechanisms in Parkinson's disease models. Crit Rev Toxicol. 2012; doi: 10.3109/10408444.2012.680431.

15. Radad K, Al-Shraim M, Al-Emam A, Wang F, Kranner B, Rausch WD, et al. Rotenone: From modelling to implication in Parkinson's disease. Folia Neuropathol. 2019; doi: 10.5114/fn.2019.89857.

16. Candello FP, Guimarães JR, Nour EAA. Earthworm avoidance behavior to antimicrobial sulfadiazine on tropical artificial soil. Ecotoxicol. Environ. Contam. 2018; doi: 10.5132/eec.2018.02.09.

17. Engelmann P, Pálinkás L, Cooper EL, Németh P. Monoclonal antibodies identify four distinct annelid leukocyte markers. Dev Comp Immunol. 2005; doi: 10.1016/j.dci.2004.10.008.

18. Alves AO, Weis GCC, Unfer TC, Assmann CE, Barbisan F, Azzolin VF, et al. Caffeinated beverages contribute to a more efficient inflammatory response: Evidence from human and earthworm immune cells. Food Chem Toxicol. 2019; doi: 10.1016/j.fct.2019.110809.

19. William-Faltaos S, Rouillard D, Lechat P, Bastian G. Cell cycle arrest and apoptosis induced by oxaliplatin (L-OHP) on four human cancer cell lines. Anticancer Res. 2006;26(3A):2093-9.

20. Takacs V, Molnar L, Klimek B, Galuszka A, Morgan AJ, Plytycz B. Exposure of Eisenia andrei (Oligochaeta; Lumbricidea) to Cadmium Polluted Soil Inhibits Earthworm Maturation and Reproduction but not 
Restoration of Experimentally Depleted Coelomocytes or Regeneration of Amputated Segments. Folia Biol (Krakow). 2016; doi:

10.3409/fb64_4.275.

21. Koziol B, Markowicz M, Kruk J, Plytycz B. Riboflavin as a Source of Autofluorescence in Eisenia fetida Coelomocytes. Photochem Photobiol. 2006; doi: 10.1562/2005-11-23-RA-738.

22. Płytycz B, Homa J, Kozioł B, Rózanowska M, Morgan AJ. Riboflavin content in autofluorescent earthworm coelomocytes is species-specific. Folia Histochem Cytobiol. 2006;44(4):275-80.

23. Bao D, Zhao J, Zhou X, Yang Q, Chen Y, Zhu J, et al. Mitochondrial fission-induced mtDNA stress promotes tumor associated macrophage infiltration and HCC progression. Oncogene. 2019; doi: 10.1038/s41388019-0772-z.

24. Koza A, Wilhelm M, Hiripi L, Elekes K, Csoknya M. Embryogenesis of the serotonergic system in the earthworm Eisenia fetida (Annelida, Oligochaeta): immunohistochemical and biochemical studies. J Comp Neurol. 2006; doi: 10.1002/cne.21008.

25. Roberts MBV. The Giant Fibre Reflex of the Earthworm, Lumbricus Terrestris L. J Exp Biol. 1962; doi: 10.1242/jeb.39.2.219.

26. Lattouf R, Younes R, Lutomski D, Naaman N, Godeau G, Senni K, et al. Picrosirius red staining: a useful tool to appraise collagen networks in normal and pathological tissues. J Histochem Cytochem. 2014; doi: $10.1369 / 0022155414545787$.

27. Wegner KA, Keikhosravi A, Eliceiri KW, Vezina CM. Fluorescence of Picrosirius Red Multiplexed With Immunohistochemistry for the Quantitative Assessment of Collagen in Tissue Sections. J Histochem Cytochem. 2017; doi: 10.1369/0022155417718541.

28. Mo X, Qiao Y, Sun Z, Sun X, Li Y. Molecular toxicity of earthworms induced by cadmium contaminated soil and biomarkers screening. $J$ Environ Sci (China). 2012; doi: 10.1016/s1001-0742(11)60957-1.

29. Zhou S, Wang Z, Klaunig JE. Caenorhabditis elegans neuron degeneration and mitochondrial suppression caused by selected environmental chemicals. Int J Biochem Mol Biol. 2013;15;4(4):191-200.

30. Subaraja M, Vanisree AJ. Aberrant neurotransmissional mRNAs in cerebral ganglions of rotenone-exposed Lumbricus terrestris exhibiting motor dysfunction and altered cognitive behavior. Environ Sci Pollut Res Int. 2019; doi: 10.1007/s11356-019-04740-y. 
31. Murai M, Miyoshi H. Current topics on inhibitors of respiratory complex I. Biochim Biophys Acta Bioenerg. 2016; doi:

10.1016/j.bbabio.2015.11.009.

32. Viswanath B, Jose SP, Squassina A, Thirthalli J, Purushottam M, Mukherjee $\mathrm{O}$, et al. Cellular models to study bipolar disorder: $\mathrm{A}$

systematic review. J Affect Disord. 2015; doi: 10.1016/j.jad.2015.05.037.

33. Machado AK, Andreazza AC, da Silva TM, Boligon AA, do Nascimento V, Scola G, et al. Neuroprotective Effects of Açaí (Euterpe oleracea Mart.) against Rotenone In Vitro Exposure. Oxid Med Cell Longev. 2016; doi: 10.1155/2016/8940850.

34. Santiago RM, Barbieiro J, Lima MMS, Dombrowski PA, Andreatini R, Vital MABF. Depressive-like behaviors alterations induced by intranigral MPTP, 6-OHDA, LPS and rotenone models of Parkinson's disease are predominantly associated with serotonin and dopamine. Prog NeuroPsychopharmacology Biol Psychiatry. 2010; doi:

10.1016/j.pnpbp.2010.06.004

35. Chen WJ, Du JK, Hu X, Yu Q, Li DX, Wang CN, et al. Protective effects of resveratrol on mitochondrial function in the hippocampus improves inflammation-induced depressive-like behavior. Physiol Behav [Internet]. 2017; doi: 10.1016/j.physbeh.2017.09.024.

36. Madiha S, Haider S. Curcumin restores rotenone induced depressive-like symptoms in animal model of neurotoxicity: assessment by social interaction test and sucrose preference test. Metab Brain Dis. 2019; doi: 10.1007/s11011-018-0352-x.

37. Antoniuk S, Bijata M, Ponimaskin E, Wlodarczyk J. Chronic unpredictable mild stress for modeling depression in rodents: Metaanalysis of model reliability. Neurosci Biobehav Rev [Internet]. 2019; doi: 10.1016/j.neubiorev.2018.12.002.

38. Eseigbe FJ, Doherty VF, Sogbanmu TO, Otitoloju AA. Histopathology alterations and lipid peroxidation as biomarkers of hydrocarbon-induced stress in earthworm, Eudrilus eugeniae. Environ Monit Assess. 2013; doi: 10.1007/s10661-012-2700-3.

39. Ijomah OO, Adesuyi AA, Njoku KL, Ojokuku SA, Moses UD, Adesuyi OO. Histopathological effects and biomarker response of earthworms, eisenia fetida, after exposure to crude oil contaminated soils. Environ Anal Health Toxicol. 2020; doi: 10.5620/eaht.2020021.

40. Shimohama S, Kawamata J. Roles of Nicotinic Acetylcholine Receptors in the Pathology and Treatment of Alzheimer's and Parkinson's Diseases. In: Akaike A, Shimohama S, Misu Y, editors. Nicotinic Acetylcholine Receptor Signaling in Neuroprotection [Internet]. Singapore: Springer; 2018. Chapter 8. p. 137-158. 
41. Bilej $M$, Procházková $P$, Silerová $M$, Josková R. Earthworm immunity. Adv Exp Med Biol. 2010; doi: 10.1007/978-1-4419-8059-5_4.

42. Santocki M, Morgan AJ, Plytycz B. Differential Time Course of Restoration of Experimentally Depleted Coelomocytes and Fluorophores in the Earthworm Eisenia andrei. Folia Biol (Krakow). 2016; doi: 10.3409/fb64_2.121.

43. Kumar V. Toll-like receptors in the pathogenesis of neuroinflammation. $J$ Neuroimmunol. 2019; doi: 10.1016/j.jneuroim.2019.03.012.

44. Singh S, Sharma A, Khajuria K, Singh J, Vig AP. Soil properties changes earthworm diversity indices in different agro-ecosystem. BMC Ecol. 2020; doi: 10.1186/s12898-020-00296-5.

45. Taborsky B, English S, Fawcett TW, Kuijper B, Leimar O, McNamara JM, et al. Towards an Evolutionary Theory of Stress Responses. Trends Ecol Evol [Internet]. 2021; doi: 10.1016/j.tree.2020.09.003.

46. Picard M, McEwen BS. Psychological Stress and Mitochondria: A Conceptual Framework. Psychosom Med. 2018; doi: 10.1097/PSY.0000000000000544.

47. Rohleder N. Stress and inflammation - The need to address the gap in the transition between acute and chronic stress effects.

Psychoneuroendocrinology. 2019; doi: 10.1016/j.psyneuen.2019.02.021.

48. Matsuzawa-Ishimoto Y, Hwang S, Cadwell K. Autophagy and Inflammation. Annu Rev Immunol. 2018; doi: 10.1146/annurev-immunol042617-053253.

49. Fernandes MS, Machado AK, Assmann CE, Andrade EN, Azzolin VF, Duarte MMMF, et al. Açaí (Euterpe oleracea Mart.) reduces the inflammatory response triggered in vitro by the antipsychotic drug olanzapine in RAW 264.7 macrophage cells. Acta Sci Pol Technol Aliment. 2021; doi: 10.17306/J.AFS.0857.

50. Cadoná FC, de Souza DV, Fontana T, Bodenstein DF, Ramos AP, Sagrillo MR, et al. Açaí (Euterpe oleracea Mart.) as a Potential Antineuroinflammatory Agent: NLRP3 Priming and Activating Signal Pathway Modulation. Mol Neurobiol. 2021; doi: 10.1007/s12035-021-02394-x.

51. Barbisan F, Azzolin VF, Monteiro GC, Teixeira CF, Mastella MH, Bueno $V$, et al. Genetic or pharmacological superoxide-hydrogen peroxide imbalances modulate the in vitro effects of lithium on glycogen synthase kinase-3ß. Gene. 2018; doi: 10.1016/j.gene.2018.02.046. 
52. Kato T. Neurobiological basis of bipolar disorder: Mitochondrial dysfunction hypothesis and beyond. Schizophr Res [Internet]. 2017; doi: 10.1016/j.schres.2016.10.037.

53. Kasahara T, Kato T. What Can Mitochondrial DNA Analysis Tell Us About Mood Disorders? Biol Psychiatry [Internet]. 2018; doi: 10.1016/j.biopsych.2017.09.010.

54. Scaini G, Andrews T, Lima CNC, Benevenuto D, Streck EL, Quevedo J. Mitochondrial dysfunction as a critical event in the pathophysiology of bipolar disorder. Mitochondrion. 2021; doi: 10.1016/j.mito.2020.12.002. 